\title{
Aspectos metodológicos e operacionais do Estágio Extramural em universidade privada no Nordeste brasileiro
}

\author{
Lucianna Leite Pequeno*; Paulo Leonardo Ponte Marques*; Ingrid Cordeiro Monte** \\ * Doutora em Saúde Coletiva, Docente do Curso de \\ Odontologia, Unifor \\ ** Doutor em Saúde Coletiva, Docente do Curso de \\ Odontologia, Unifor \\ *** Mestra em Odontologia, Unifor
}

Recebido: 08/06/2021. Aprovado: 23/08/2021.

\begin{abstract}
RESUMO
Este relato tem por objetivo descrever os aspectos metodológicos e operacionais de um Estágio Curricular Supervisionado. O cenário foi de uma universidade privada do município de Fortaleza, Ceará, e os campos de estágio externos pactuados com órgãos governamentais e instituições não governamentais. A referência foi o período dos últimos cinco anos (2016 a 2021). O estágio ocorre com carga horária de 144 horas e operacionalização em três momentos: Prólogo (10\% do tempo), Mundo Real (80\%) e Epílogo (10\%). No Prólogo são desenvolvidas atividades de resgate e nivelamento de conhecimentos e ações realizadas durante o curso. A operacionalização do estágio, a partir da articulação teoria e prática, ocorre no momento do Mundo Real. Os discentes são alocados em turmas de 5 a 6 componentes para atuar 8 horas por semana em campos de estágio do Sistema Único de Saúde. São desenvolvidas ações coletivas em espaços sociais e procedimentos clínicoassistenciais nos consultórios odontológicos das Unidades de Saúde. Mediado pelo docente e preceptor, ocorrem feedbacks em grupo para troca de experiências semanalmente. No Epílogo há o fechamento do estágio, por meio da devolutiva em forma de apresentação da Mostra e de relatórios das atividades realizadas. A diversidade de estratégias metodológicas e operacionais do estágio possibilita uma imersão diferenciada dos discentes nos serviços públicos de saúde, proporcionando que a teoria encontre a prática para aquisição de competências que serão aplicadas no Mundo Real.

Descritores: Formação Profissional. Estudantes de Odontologia. Sistema Único de Saúde. Saúde Pública.
\end{abstract}

\section{INTRODUÇÃO}

O ensino nos cursos de graduação em Odontologia, de forma geral, ainda se encontra focado em clínicas modelo e aparatos tecnológicos capazes de potencializar o aprendizado em condições ideais ${ }^{1,2}$. No entanto, ao se deparar com a realidade, os alunos de graduação dos últimos semestres observam que as condições reais agregam uma série de dificuldades. Entre os desafios a serem enfrentados se encontram o reconhecimento de diferentes territórios e suas dinâmicas sociais, necessidades de melhorias estruturais em unidades de saúde e a articulação interprofissional. 
Apesar das conquistas alcançadas nas últimas décadas ${ }^{3}$, a inversão do modelo assistencial focado em práticas curativistas continua sendo um horizonte a ser almejado na saúde bucal. Mesmo com diversas iniciativas para incorporação das bases da Saúde Coletiva nos currículos acadêmicos da área da saúde, prevalece a preferência pela clínica odontológica individualizada em uma lógica de trabalho com ideário liberal-privatista ${ }^{4,5}$.

Ao permitir que o aluno rompa a barreira intramural, os domínios atitudinais, de habilidades e de conexões entre a teoria e a prática vão ganhando novos sentidos em diferentes níveis de complexidade $^{6}$. O aprofundamento das vivências fora da universidade é capaz de elevar o nível de autonomia, maturidade cidadã e acadêmica dos discentes ${ }^{7}$.

O Sistema Único de Saúde (SUS), com seus pontos de atenção, ações e serviços, constitui um campo de aprendizado e etapa obrigatória na formação do bacharel em Odontologia ${ }^{8}$. Suas fragilidades, potencialidades e conquistas indiscutíveis desde a sua implementação", produzem um cenário desafiador, independentemente de ser o primeiro contato durante a formação do estudante ou de ser um profissional que já atua no serviço há décadas.

Desta forma, os aspectos metodológicos e operacionais de módulos que se desenvolvem em espaços extramuros, devem ser cuidadosamente pensados com o uso de metodologias ativas abrangentes e que permitem aprendizagem, a partir da compreensão da realidade local ${ }^{10}$. Esses direcionamentos utilizam como suporte a abordagem na promoção da saúde, assegurada em práticas integradas e contínuas que possam, de forma socialmente sensível, contribuir para a melhoria da condição de saúde da população ${ }^{8}$.

Diante de um cenário em que a diversidade de estratégias pode contribuir para uma melhor formação em Odontologia, este artigo tem por objetivo relatar os aspectos metodológicos e operacionais do Estágio Curricular Supervisionado de uma universidade privada no Sistema Único de Saúde.

\section{RELATO DE EXPERIÊNCIA}

Trata-se de um relato da experiência a partir das atividades vivenciadas por alunos e equipe docente do Estágio Curricular Supervisionado (ECS) denominado Estágio Extramural do Curso de Odontologia de uma universidade do nordeste brasileiro. Inserido no eixo da Saúde Coletiva, o ECS é um módulo obrigatório, regido por resolução própria do Conselho de Ensino, Pesquisa e Extensão da universidade. Caracteriza-se pelo desenvolvimento de habilidades para o exercício profissional em atividades externas e cujo acompanhamento processual é realizado pela supervisão e orientação dos docentes.

O ECS tem como objetivo geral desenvolver ações de atenção à saúde geral e bucal no âmbito de instituições públicas, privadas e/ou filantrópicas, baseando-se no planejamento estratégico situacional aplicado no contexto da promoção e prevenção de saúde, em parceria com gestores, equipes de saúde e comunidade.

Quanto aos aspectos metodológicos, o módulo é organizado em 08 créditos práticos, com carga horária de 144 horas (8 horas semanais). A equipe docente é composta por 07 professores, sendo 2 com mestrado e 5 com doutorado em áreas de concentração da Saúde Coletiva. Os docentes são alocados em turmas, média de 10 por semestre, que comportam equipes com 5 ou 6 alunos.

O plano de ensino semestral é discutido coletivamente com a equipe docente, que faz sugestões e ajustes a cada semestre com base na avaliação discente do semestre anterior e experiências vivenciadas nos campos de estágio. Em seguida, o plano é analisado e revisado por uma equipe do Núcleo Docente vinculada à coordenação do curso. O quadro 1 apresenta os objetivos, unidades temáticas e carga horária 
semestral para o ECS do curso de Odontologia.

No primeiro encontro com os alunos, a equipe docente apresenta o plano de ensino para os discentes. As turmas são agrupadas para que sejam discutidos os objetivos de aprendizagem, a dinâmica de funcionamento, os tipos e locais do estágio, o processo de avaliação e o cronograma da disciplina. Neste dia é firmado um acordo de convivência considerando frequência, horário, vestimenta, possibilidade de reposição de atividades e como dirimir quaisquer dúvidas.

Cada turma passa a ter contato permanente com o docente, por meio do sistema da universidade, que permite o envio e o recebimento de torpedos. Associado a esse sistema, os discentes são apresentados à plataforma virtual implantada desde 2020, o Ambiente Virtual de Aprendizagem (AVA) no Moodle. Todo o material de apoio fica disponibilizado no AVA, assim como a bibliografia utilizada, a qual é concentrada em livros, artigos, manuais, notas técnicas e portarias no âmbito da Saúde Coletiva e políticas de saúde.

As atividades do ECS podem ser categorizadas em três momentos distintos, conforme organização do calendário acadêmico. $\mathrm{O}$ prólogo, realizado no início do semestre, para resgate de temáticas discutidas durante o curso, calibração e orientação prévia à entrada nos campos de estágio. Em seguida, o mundo real, para realização das atividades nestes campos; e o epílogo, no final do semestre, para fechamento das atividades, consolidação de relatórios, e apresentação da mostra do estágio. Cada um desses momentos será descrito a seguir.

\section{Momento 1 - prólogo}

O prólogo compreende duas semanas intensas de compartilhamento de vivência dos docentes e resgate dos referenciais teóricos em Saúde Coletiva, correspondendo a uma carga horária de 10\% do módulo de Estágio. Apesar do certo enfoque teórico, tem como propósito a aproximação dos discentes com o corpo docente e compartilhamento de experiências dos docentes em atividades nos semestres anteriores com base em temáticas previstas no plano de ensino: Política Nacional de Atenção Básica, Política Nacional de Saúde Bucal, Epidemiologia e Sistemas de Prevenção, Guia de Procedimentos Operacionais Padrão e Humanização.

O quadro 2 apresenta as temáticas, estratégias e metodologias utilizadas durante essas atividades do Momento 1.

Essas atividades são elaboradas a partir do referencial metodológico da problematização, com associação de estratégias ou técnicas teóricopráticas que permitam ao estagiário aprimorar seu arsenal de estratégias para aplicação nos campos de estágio. As metodologias de ensino-aprendizagem com participação ativa possibilitam um resgate para integração de conhecimentos entre os eixos das ciências básicas e o eixo profissionalizante ${ }^{11}$. A operacionalização das atividades iniciais ocorre no formato híbrido, com atividades obrigatórias presenciais e atividades complementares virtuais desenvolvidas na plataforma do Ambiente Virtual de Aprendizagem do Moodle.

Ao final dessas semanas e previamente à entrada dos discentes nos campos de estágio, é aplicado um teste cognitivo por meio da ferramenta questionário do Moodle. A maioria das questões envolve situações-problema que os discentes podem enfrentar nos serviços de saúde. Embora a avaliação do estágio seja predominantemente prática e realizada de forma processual, o resultado do teste cognitivo é uma das referências que os docentes do ECS utilizam para identificar oportunidade de melhoria no aprofundamento teórico-prático.

\section{Momento 2 - mundo real}

$\mathrm{O}$ mundo real corresponde a operacionalização do estágio em si. Utilizou-se essa denominação para o momento 2 por ser uma 
Quadro 1. Objetivos, temáticas e carga horária do ECS

\begin{tabular}{|c|c|c|}
\hline Temática & Objetivos & $\begin{array}{c}\text { Carga } \\
\text { horária }\end{array}$ \\
\hline $\begin{array}{l}\text { UNIDADE I - Redes de atenção em saúde } \\
\text { - Redes de atenção e linhas do cuidado. } \\
\text { - Monitoramento e avaliação das ações de } \\
\text { saúde. }\end{array}$ & $\begin{array}{l}\text { Relacionar com os níveis do cuidado nas redes } \\
\text { de atenção em saúde. } \\
\text { Utilizar as informações em saúde para } \\
\text { planejamento e avaliação/monitoramento das } \\
\text { ações de saúde. }\end{array}$ & $12 \mathrm{~h}$ \\
\hline $\begin{array}{c}\text { UNIDADE II - Humanização na saúde } \\
\text { - Integração dos alunos, profissionais de saúde e } \\
\text { usuários dos serviços. } \\
\text { - Atitudes e habilidades de relacionamento } \\
\text { aluno-profissional de saúde-usuário. }\end{array}$ & $\begin{array}{l}\text { Ser ético no cuidado em saúde em equipes } \\
\text { multiprofissionais. }\end{array}$ & $10 \mathrm{~h}$ \\
\hline $\begin{array}{c}\text { UNIDADE III - Diagnóstico situacional em } \\
\text { saúde } \\
\text { - Diagnóstico situacional em unidades de } \\
\text { atenção primária à saúde e/ou instituições. } \\
\text { - Composição, organização, estrutura e } \\
\text { capacidade. } \\
\text { - Cobertura, acessibilidade e aceitabilidade. } \\
\text { - Serviços e atividades realizadas. } \\
\text { - Recursos humanos. }\end{array}$ & $\begin{array}{c}\text { Realizar diagnóstico situacional de unidades de } \\
\text { atenção primária à saúde e/ou instituições, a } \\
\text { partir do reconhecimento da necessidade local, } \\
\text { sob o referencial epidemiológico e de } \\
\text { planejamento estratégico. } \\
\text { Adotar atitude ética e humana em contexto de } \\
\text { atuação nos serviços de saúde. }\end{array}$ & $8 \mathrm{~h}$ \\
\hline $\begin{array}{c}\text { UNIDADE IV - Planejamento em saúde em } \\
\text { unidades de atenção primária à saúde e/ou } \\
\text { instituições } \\
\text { - Planejamento estratégico em saúde. } \\
\text { - Interdisciplinaridade. } \\
\text { - Participação popular. } \\
\text { - Ações integradas em saúde. }\end{array}$ & $\begin{array}{c}\text { Executar um planejamento estratégico- } \\
\text { situacional, a partir da integração com a } \\
\text { comunidade e demais profissionais de saúde em } \\
\text { unidades de atenção primária à saúde e/ou } \\
\text { instituições. } \\
\text { Respeitar os princípios éticos e a articulação das } \\
\text { ações planejadas ao contexto social e cidadão. }\end{array}$ & $8 \mathrm{~h}$ \\
\hline $\begin{array}{l}\text { UNIDADE V - Atenção em Saúde } \\
\text { - Acolhimento com classificação de risco. } \\
\text { - Atividades preventivas e educativas. } \\
\text { - Atenção e assistência em saúde bucal. }\end{array}$ & $\begin{array}{l}\text { Desenvolver ações de atenção em saúde, e em } \\
\text { particular, em saúde bucal, nas unidades de } \\
\text { atenção primária à saúde e/ou instituições, a } \\
\text { partir do planejamento estratégico realizado. } \\
\text { Ser ético na execução de ações de saúde e saúde } \\
\text { bucal. }\end{array}$ & $94 \mathrm{~h}$ \\
\hline $\begin{array}{l}\text { UNIDADE VI - Intervenção em saúde bucal } \\
\text { Diagnóstico situacional. } \\
\text { Planejamento de estratégias e ações em saúde. } \\
\text { Indicadores de monitoramento e avaliação em } \\
\text { saúde. }\end{array}$ & Propor um plano de intervenção em saúde bucal. & $12 \mathrm{~h}$ \\
\hline
\end{tabular}


Quadro 2. Temáticas e aspectos metodológicos do Momento 1

\begin{tabular}{|c|c|c|}
\hline Temática & Objetivos específicos & Aspectos metodológicos \\
\hline $\begin{array}{l}\text { Atenção Primária } \\
\text { à Saúde e Roteiro } \\
\text { para Diagnóstico } \\
\text { Situacional }\end{array}$ & $\begin{array}{l}\text { Compreender os pressupostos para } \\
\text { reorientação da atenção básica no Brasil; } \\
\text { discutir sobre os princípios e diretrizes da } \\
\text { Política Nacional de Atenção Básica; descrever } \\
\text { o processo de trabalho na atenção básica. }\end{array}$ & $\begin{array}{l}\text { Leitura da PNAB; construção de um painel na } \\
\text { sala com lousa } 360^{\circ} \text {; apresentação do painel } \\
\text { discussão com a turma; elaboração de roteiro } \\
\text { semiestruturado para aplicação com o } \\
\text { preceptor no campo de estágio }\end{array}$ \\
\hline $\begin{array}{l}\text { Política Nacional } \\
\text { de Saúde Bucal }\end{array}$ & $\begin{array}{l}\text { Discutir sobre os princípios e diretrizes da } \\
\text { Política Nacional de Saúde Bucal; descrever o } \\
\text { processo de trabalho e ações nos níveis de } \\
\text { atenção; compreender os pressupostos para } \\
\text { reorientação do modelo de atenção em saúde. }\end{array}$ & $\begin{array}{l}\text { Leitura da PNSB; gamificação com a } \\
\text { ferramenta Socrative: com o uso do } \\
\text { smartphone cada discente responderá, } \\
\text { individualmente e, em seguida em grupo, } \\
\text { questões de múltipla escolha; apresentação dos } \\
\text { resultados e premiação aos vencedores; } \\
\text { discussão com a turma }\end{array}$ \\
\hline $\begin{array}{ll}\text { Epidemiologia } & \text { e } \\
\text { Sistemas de } \\
\text { Prevenção }\end{array}$ & $\begin{array}{l}\text { Interpretar gráficos e realizar análise } \\
\text { epidemiológicas em saúde geral e bucal; } \\
\text { discutir a importância das interpretações e } \\
\text { análises epidemiológicas para o planejamento } \\
\text { e execução da atenção em saúde. }\end{array}$ & $\begin{array}{l}\text { Acesso ao Ambiente Virtual de } \\
\text { Aprendizagem; estudo dos referenciais } \\
\text { teóricos indicados; realização de estudo } \\
\text { dirigido com questões sobre epidemiologia } \\
\text { geral e bucal; discussão em grupo em formato } \\
\text { presencial }\end{array}$ \\
\hline $\begin{array}{l}\text { Saúde Bucal no } \\
\text { SUS }\end{array}$ & $\begin{array}{l}\text { Compreender a atuação em saúde bucal de } \\
\text { indivíduos e grupos populacionais em diversos } \\
\text { ciclos e condições de vida; discutir a } \\
\text { importância do planejamento e programação } \\
\text { em saúde bucal; compreender o processo de } \\
\text { trabalho das equipes de saúde conforme os } \\
\text { ciclos e condições de vida; reconhecer os } \\
\text { pontos de atenção da saúde bucal da Rede de } \\
\text { Atenção à Saúde }\end{array}$ & $\begin{array}{l}\text { Recebimento de situações problemas sobre } \\
\text { grupos específicos e condições de vida em } \\
\text { contexto real; construção de uma proposta de } \\
\text { resolução da situação; apresentação da } \\
\text { proposta de resolução; discussão com a turma }\end{array}$ \\
\hline $\begin{array}{l}\text { Guia } \quad \text { de } \\
\text { Procedimentos } \\
\text { em } \quad \text { Saúde } \\
\text { Coletiva }\end{array}$ & $\begin{array}{l}\text { Discutir sobre o Guia de Procedimentos como } \\
\text { forma de padronizar os aspectos operacionais } \\
\text { das ações coletivas: Ação coletiva de exame } \\
\text { bucal com finalidade epidemiológica e } \\
\text { Atividade Educativa; Ação coletiva de } \\
\text { escovação supervisionada, Aplicação Tópica } \\
\text { de Flúor; Pré-natal odontológico; Consulta de } \\
\text { Puericultura; Tratamento restaurador } \\
\text { atraumático }\end{array}$ & $\begin{array}{l}\text { Recebimento do Guia de Procedimentos em } \\
\text { Saúde Coletiva da universidade; análise e } \\
\text { discussão sobre os procedimentos em } \\
\text { pequenos grupos envolvendo finalidade, } \\
\text { materiais, forma de organização, passo a } \\
\text { passo; apresentação da síntese da discussão } \\
\text { para o desenvolvimento das ações; discussão } \\
\text { com a turma; incorporação de } \\
\text { ajustes/atualização no Guia de Procedimentos }\end{array}$ \\
\hline $\begin{array}{l}\text { Humanização } \\
\text { em Saúde }\end{array}$ & $\begin{array}{l}\text { Refletir sobre a humanização em saúde } \\
\text { Integrar alunos, profissionais de saúde e } \\
\text { usuários dos serviços e o desenvolvimento de } \\
\text { atitudes e habilidades de relacionamento aluno- } \\
\text { profissional de saúde-usuário. }\end{array}$ & $\begin{array}{l}\text { Acesso ao Ambiente Virtual de } \\
\text { Aprendizagem; estudo dos referenciais } \\
\text { teóricos e vídeos indicados; discussão com } \\
\text { participação dos preceptores de estágio; } \\
\text { construção de texto-sentido: "Como sou } \\
\text { profissionalmente" com foco na humanização } \\
\text { em saúde e condutas pessoais. }\end{array}$ \\
\hline
\end{tabular}


expressão utilizada de forma rotineira pelos discentes para diferenciar do ambiente das clínicas odontológicas intramuros na universidade. O momento 2 corresponde a $80 \%$ da carga horária do módulo de estágio.

Antes do início do semestre letivo, a equipe docente já articula junto com os coordenadores das Instituições para Grupos Específicos (IGE) e de Unidades de Atenção Primária à Saúde (UAPS) a pactuação de dias e horários para recebimento das turmas de estágio. Nesse momento também é feita a identificação e convite a profissionais do serviço para atuarem como preceptores junto a equipe docente.

Para cada turma de estágio é designada uma UAPS do município de Fortaleza, a qual será o campo de estágio principal para realização de atividades clínico-assistenciais e coletivas durante todo o semestre. A seleção dessas UAPS ocorre a partir da proximidade territorial com a Universidade, disponibilidade de preceptor para acompanhamento do estágio e pactuação com a Secretaria Municipal de Saúde.

Para o registro das experiências vivenciadas no estágio cada turma e cada docente recebe um diário de campo para registro das atividades. $\mathrm{O}$ diário dos estagiários assemelha-se a um portfólio com caráter descritivo e reflexivo sobre as ações realizadas, sendo dividido em quatro partes: atividades planejadas, atividades realizadas, registro da agenda de atendimentos e registro dos procedimentos realizados nos prontuários da UAPS. O diário é utilizado como ferramenta para registro do dia a dia do estágio e a responsabilidade do preenchimento deve ser compartilhada pela turma. Já no diário de campo do docente são registradas as observações referentes a atuação dos estagiários, de acordo com os critérios e objetivos de aprendizagem previstos, facilitando o processo de avaliação.

A primeira atividade realizada extramuros é o reconhecimento da unidade e do território adstrito, durante a qual faz-se a observação do campo, entrevista com informantes-chaves e planejamento das atividades. Nesse momento muitos estagiários recordam de práticas dos módulos de Saúde Coletiva que trataram da importância de se observar a realidade e de se propor estratégias condizentes com a necessidade identificada. Estruturada na problematização, essa metodologia estimula a atuação responsável e consciente no processo de cuidado de diferentes perfis populacionais e, ao mesmo tempo, motiva a formação de profissionais mais humanos e reflexivos para atuar no SUS ${ }^{12,13}$.

Com os informantes-chaves, os alunos fazem uma entrevista, a partir de um roteiro semiestruturado construído pelo próprio grupo durante atividade de discussão sobre a PNAB. Entre esses informantes, o que os estagiários passam a ter mais contato é o cirurgião-dentista preceptor, denominação utilizada para se referir ao profissional do município convidado a colaborar no processo de ensino-aprendizagem do estágio juntamente com os docentes. O convite aos preceptores, que atuam de forma voluntária, leva em consideração o perfil de atuação na APS, capacitação, motivação e disponibilidade de tempo.

A identificação desses profissionais torna-se relevante para a formação e uma melhor integração nos campos de estágio ${ }^{6}$. Estudo realizado em unidades de saúde de um município no Paraná apontou que parte dos cirurgiões-dentistas preceptores não se sentem capacitados e incentivados para exercer a função, sendo necessário aprimorar a integração ensino-serviço para uma melhor qualidade na formação profissional $^{14}$.

Após o reconhecimento e com mediação do docente, os discentes iniciam o planejamento utilizando uma chuva de ideias com o registro de 
possíveis causas e consequências do cenário observado para, em seguida, discutir possibilidades de atuação. Para facilitar o processo e estimular a proposição de intervenções, entre as ferramentas mais utilizadas se encontra o plano de ação no modelo $5 \mathrm{~W} 2 \mathrm{H}$, constituído por 7 perguntas básicas na língua inglesa (what; where; who; when; why; how; how much) que devem ser respondidas e registradas previamente pelos estagiários para cada atividade que pretendem realizar. $\mathrm{O} 5 \mathrm{~W} 2 \mathrm{H}$ é uma ferramenta de fácil aplicação e tem sido utilizado também como instrumento de direcionamento nos processos gerenciais de serviços de saúde ${ }^{15}$.

A partir do calendário acadêmico e considerando a carga horária do estágio, os discentes constroem a programação semanal de atividades com vistas a cumprir os objetivos do ECS. Nesse momento, também ocorre a divisão de tarefas e responsabilidades para todos os envolvidos no processo. Experiências exitosas de planejamento em conjunto com o serviço, incluindo a participação dos preceptores como facilitadores do processo de ensino-aprendizagem, foram relatadas de forma positiva para resolutividades das demandas sociais em Feira de Santana-Bahia ${ }^{16}$.

O planejamento das ações coletivas é voltado para identificação das necessidades da população adstrita, com foco nas linhas de cuidado ou condição de vida. Mesmo diante de algumas restrições devido ao cenário pandêmico, uma atividade rotineira do ECS é a visita domiciliar no território. Partindo de dados fornecidos pelos Agentes Comunitários de Saúde (ACS) sobre o perfil epidemiológico geral das microáreas, os estagiários mapeiam e identificam os pacientes domiciliados e acamados que necessitam receber visita da equipe. As visitas são programadas com dois estagiários de Odontologia acompanhados pelo docente ou pelo preceptor, e em conjunto com o ACS e outros profissionais da Equipe de Saúde da Família (ESF).
Embora a atenção domiciliar não seja uma ação estratégica rotineira das equipes de saúde bucal, esse tipo de cuidado possibilita uma assistência diferenciada para grupos que se encontram impossibilitados de acessar os consultórios $^{17}$. Nesse cenário, as visitas proporcionam satisfação ao usuário ao respeitar as necessidades locais e edificar o valor em saúde bucal para os assistidos ${ }^{18}$.

Quando possível, estagiários de outros cursos de graduação, inclusive de diferentes instituições de ensino, são integrados às atividades do estágio, possibilitando múltiplas conquistas. De um lado beneficia a comunidade local e fortalece os serviços, e de outro transpõe o modelo de formação fragmentado e desperta nos discentes uma consciência coletiva em prol da melhoria da qualidade de vida da população ${ }^{19,2}$.

Nesse contexto, atividades educativas com temáticas sazonais (Setembro Amarelo, Outubro Rosa, Novembro Azul) agregaram novos conhecimentos e tiraram os estagiários da zona de conforto de sua formação tradicional. Esse olhar além da boca experienciado também na forma de clínica ampliada extrapola o "odontocentrismo", além de criar um ambiente para abandono de concepções antigas e abrir espaços para atualização dos processos de trabalho ${ }^{20}$.

Outro planejamento que tem sido recorrente para as últimas turmas é a realização de atividades de Educação Permanente. Voltada para os preceptores e outros profissionais do serviço, destacam-se cursos em formato híbrido (presencial e/ou à distância) com atividades síncronas e assíncronas. Mediados pelos estagiários nas salas de reuniões das UAPS ou na plataforma do Google Classroom, já foram realizados cursos sobre cuidados em saúde bucal para o ACS, curso sobre biossegurança e esterilização, curso de monitoramento de indicadores por meio de planilhas eletrônicas, curso de urgências no ambiente escolar, dentre outros. 
Durante o planejamento das atividades clínicas, a turma seleciona os pacientes a serem beneficiados e a forma de captação, geralmente ocorrendo por meio de atividades no território e com a busca de perfil de necessidade da Atenção Primária à Saúde. Outra possibilidade de seleção ocorre por meio da utilização da agenda de pacientes já captados previamente pelo preceptor ou agendados diretamente na recepção da UAPS.

Para a realização dos atendimentos clínicos nos consultórios odontológicos os alunos são divididos em duplas. O restante da turma realiza ações coletivas na própria unidade, em espaços sociais ou nos domicílios. Desta forma, as quatro horas semanais previstas nas UAPS são distribuídas de forma que sempre dois estagiários atuem na clínica e os outros estagiários da turma desenvolvam ações extra clínicas, havendo sistema de rodízio a cada semana.

Já nas IGE, os estagiários têm a possibilidade de atuar as outras quatro horas semanais em espaços com idosos, crianças em condição de vulnerabilidade social, adolescentes, gestantes, puérperas, pessoas com deficiência, pacientes hospitalizados, pacientes psiquiátricos, entre outros. Cada turma desenvolve ações coletivas e/ou procedimentos clínicos a depender da estrutura local. Nas ações coletivas são utilizadas diferentes temáticas e metodologias visando a troca de conhecimentos para promoção da saúde nos ciclos de vida.

Estudo com graduandos no estágio em Saúde Coletiva na Bahia identificou a atuação semanal com diferentes grupos. A interação com o público foi realizada de forma mais destacada por meio de oficinas, rodas de conversa e atividades educativas na sala de espera ${ }^{16}$.

Nas instituições que atuam com crianças e adolescentes, a exemplo do Instituto da Primeira Infância (IPREDE), o Centro de Atenção Psicossocial Infantil (CAPSi), Projeto Social Sementes da Criança e Adolescência (PROSSICA) e Associação de Pais e Amigos dos Excepcionais (APAE), realizam-se atividades lúdicas e que buscam ampliar o vínculo para uma participação conjunta entre os pais e a criança. Destacam-se álbuns seriados construídos pelos estagiários; mesas demonstrativas com macromodelos e produtos de higiene bucal; teatro de fantoches para abordar a prevenção das principais doenças bucais; e atividades lúdicas em espaços abertos.

Experiência desenvolvida em Maringá (Paraná) com alunos do estágio da Odontologia, destacaram a importância de promover a aprendizagem nas atividades educativas de forma mais abrangente, sensibilizando para a mudanças comportamentais e melhoria da qualidade de vida. A utilização de painéis ilustrativos com informações sobre as principais doenças bucais também foi relatada como contributiva para a realidade dos participantes ${ }^{21}$.

Durante o estágio na APAE os discentes também realizam atendimento clínico das pessoas com deficiência com a oferta de procedimentos odontológicos básicos como instrução de higiene bucal, restauração, exodontia, controle da cárie, por meio do uso de cariostático e aplicação tópica de flúor gel ou verniz. Por sua vez, no Núcleo de Atenção Médica Integrada (NAMI), na instituição para idosos Lar Torres de Melo e no Hospital Gonzaguinha de Messejana os alunos realizam atividades educativas para os usuários na sala de espera e nos leitos com o objetivo de orientar sobre os principais cuidados com a saúde bucal.

Apesar da necessidade da resolução das demandas clínicas dos pacientes e da importância do atendimento odontológico para o aprendizado do estagiário, os momentos de educação em saúde na sala de espera são de extrema valia, pois proporcionam a aproximação do discente com o contexto de vida da família do paciente, permitindo o conhecimento de determinantes e condicionantes da saúde da pessoa com deficiência.

O acompanhamento supervisionado é 
realizado pelos docentes diariamente $\mathrm{e}$ as intervenções para recondução de conduta dos estagiários durante a realização das atividades só acontece em caso de violação dos objetivos do estágio, normas do local ou problemas éticos. Isso possibilita a vivência de situações reais e o aprendizado com os próprios erros, que por sua vez são discutidos no encerramento de cada turno de estágio. As observações do docente são registradas em um outro diário de campo, exclusivo do professor.

Tanto nas UAPS quanto nas instituições, após a finalização das atividades previstas em cada turno de estágio, o docente, o preceptor e os discentes fazem uma discussão de casos, relatam as situações vivenciadas articulando com a literatura científica e fazem reflexões sobre as atitudes éticas e humanas no contexto de atuação.

\section{Momento 3 - epílogo}

O epílogo do ECS corresponde as atividades de finalização do estágio, compreendendo a construção dos relatórios e apresentação da Mostra de atividades realizadas no semestre.

A oficina dos relatórios é realizada com mediação do docente, que fornece um modelo de layout com pré-requisitos mínimos a serem inseridos no relatório da turma. Com base nos registros no diário de campo e vivência nas atividades ao longo do semestre, os discentes constroem um relatório contendo introdução, localização do campo de estágio, descrição das atividades planejadas, registro de atividades, material utilizado, quantitativo de procedimentos e ações realizados, população beneficiada e conclusão. Já a Mostra do estágio é uma atividade em que os dados registrados nos relatórios são transportados para uma apresentação em formato power point ou painel. Conforme previsto no cronograma, os discentes reservam um local no próprio campo de estágio, geralmente auditórios ou salas de reuniões, para fazer a devolutiva para gerentes, preceptores e outros profissionais e funcionários do serviço.

Essa atividade surpreende pessoas convidadas que não acompanharam o estágio ao longo do semestre, pois possibilita uma prestação de contas detalhadas das ações desenvolvidas e ainda a sugestão de melhorias em atividades futuras. Durante a Mostra também são relatadas as dificuldades superadas quanto aos aspectos atitudinais no trabalho em equipe $\mathrm{e}$ relacionamento interprofissional, assim como o desenvolvimento de habilidades na realização do planejamento de diferentes atividades a cada semana, assumir posição de liderança e utilizar técnicas adequadas de acordo com cada cenário e público participante.

As dificuldades de desenvolvimento atitudinal e de habilidades apontam para a relevância do estágio, com reconhecimento de diferença na metodologia adotada frente às disciplinas cursadas até então. Do ponto de vista da formação, denota a importância na reorientação das práticas tecnicistas, descontextualizadas da realidade e centradas no docente para a valorização do aluno enquanto cidadão apto enfrentar problemas ${ }^{21}$. Para superar isso, a mais profunda essência do ensino precisa continuar enfrentando o desafio de conquistar o interesse do estudante para além do conteúdo, buscando a construção, desconstrução e reconstrução de sujeitos ativos ${ }^{10}$.

\section{Processo Avaliativo}

Quanto aos aspectos avaliativos, são utilizadas variadas formas de avaliar o discente de forma processual. Para efeito de aprovação, considera-se que a frequência necessária para aprovação é de no mínimo $90 \%$ do total da carga horária e sete como nota mínima. $\mathrm{O}$ aluno é avaliado nas seguintes proporções e domínios: cognitivo (30\%), habilidades $(30 \%)$ e atitudes (40\%) (quadro 3). 
Quadro 3. Critérios de avaliação do ECS

\begin{tabular}{|c|c|c|c|c|}
\hline \multicolumn{3}{|c|}{ Atitude (40\%) } & $\begin{array}{c}\text { Habilidade } \\
(30 \%)\end{array}$ & Cognitivo (30\%) \\
\hline $\begin{array}{c}\text { Pontualidade } \\
(10 \%)\end{array}$ & $\begin{array}{l}\text { Relacional } \\
(10 \%)\end{array}$ & $\begin{array}{c}\text { Participação } \\
(20 \%)\end{array}$ & Saber fazer & Referencial Teórico \\
\hline Pontualidade & $\begin{array}{l}\text { Trabalho em } \\
\text { equipe. } \\
\text { Entusiasmo. } \\
\text { Relacionar- } \\
\text { se com } \\
\text { profissionais, } \\
\text { funcionários, } \\
\text { colegas e } \\
\text { comunidade. } \\
\text { Ética e } \\
\text { colaboracão }\end{array}$ & $\begin{array}{c}\text { Motivação } \\
\text { Proatividade } \\
\text { Criatividade. } \\
\text { Responsabilidade } \\
\text { Compromisso }\end{array}$ & $\begin{array}{c}\text { Utilização de } \\
\text { técnicas } \\
\text { adequadas. } \\
\text { Uso de EPI. } \\
\text { Liderança. } \\
\text { Comunicar-se } \\
\text { adequadamente } \\
\text { de } \\
\text { Elaboração de } \\
\text { plano de ação. }\end{array}$ & $\begin{array}{c}\text { Capacidade de associação } \\
\text { teórico-prática } \\
\text { Planejamento com base nos } \\
\text { dados encontrados e roteiros } \\
\text { propostos } \\
\text { Segurança em cumprir as } \\
\text { atividades } \\
\text { Desenvolvimento de um } \\
\text { pensamento crítico e reflexivo }\end{array}$ \\
\hline
\end{tabular}

Esses critérios são utilizados diariamente em forma de checklist para avaliar todas as atividades do estágio de forma mais objetiva. A avaliação do domínio cognitivo ocorre nos três momentos do estágio: pelos conhecimentos prévios no prólogo; pela associação, contextualização e uso do referencial teórico durante as atividades práticas no mundo real; e pela demonstração dos conhecimentos adquiridos nas atividades do epílogo.

O domínio atitudinal é avaliado pelos seguintes aspectos: motivação, interesse, entusiasmo, relacionamento interpessoal; interação e integração do aluno; capacidade de criatividade, iniciativa e liderança. Já quanto à habilidade, são consideradas utilização de técnicas adequadas, uso correto dos equipamentos de proteção individual, liderança, comunicar-se adequadamente de acordo com o público-alvo, e elaboração de plano de ação. Todos os critérios são registrados de forma descritiva no diário de campo do docente, que avalia os estagiários de forma individual e coletiva.

Para efeitos de processo avaliativo, cabe ao docente interpretar o instrumento e os critérios utilizados para aferir o aprendizado de forma justa.
Essa avaliação deve ser dinâmica e centrada na aprendizagem no dia a dia com a finalidade de aferir a progressão ao longo do tempo. Tomando como base o diálogo permanente e favorecendo a capacidade de desenvolvimento individual, o aluno passa a assumir um papel mais ativo ${ }^{22}$ possibilitando uma preocupação não apenas com uma nota, mas sim com a transformação da realidade local.

\section{CONSIDERAÇÕES FINAIS}

A diversidade de estratégias metodológicas e operacionais do Estágio Supervisionado relatado possibilita uma imersão diferenciada dos discentes no cenário dos serviços públicos de saúde, proporcionando a construção de uma atmosfera onde a teoria se encontra com a prática para aquisição de competências que serão aplicadas no mundo real.

\section{ABSTRACT \\ Methodological and operational aspects of the Extra Mural Internship at a Private University in Northeastern Brazil \\ This report aims to define the methodological and}


operational aspects of a Supervised Curricular Internship. The setting was of a private university in the city of Fortaleza-Ceará, and the external internship fields agreed with government agencies and non-governmental institutions. The reference was the period of the last five years (2016 to 2021). The internship takes place with a workload of 144 hours and is operationalized in three moments: Prologue (10\% of the time), Real World (80\%) and Epilogue (10\%). In the Prologue there are activities developed for the recovery and leveling of knowledge and actions carried out during the course. The operationalization of the internship from the articulation of theory and practice takes place at the time of the Real World. Students are allocated in groups of 5 to 6 components to work 8 hours a week in internship fields of the Unified Health System. Collective actions are developed in social spaces and clinical-assistance procedures in the dental offices of the Health Units. and preceptor, there are group feedbacks to exchange experiences weekly. In the Epilogue, the internship is closed, through feedback in the form of presentation of the exhibition and reports of the activities carried out. The diversity of methodological and operational strategies of the internship enables a differentiation of students in public health services, allowing a theory to find the practice for the acquisition of skills that will be applied in the Real World.

Descriptors: Professional Training. Students, Dental. Unified Health System. Public Health.

\section{REFERÊNCIAS}

1. Lage RH, de Almeida SKTT, Vasconcelos GAN, Assaf AV, Robles FRP. Ensino e aprendizagem em odontologia: análise de Sujeitos e Práticas. Rev Bras Educ Med. 2017;41(1): 22-9.

2. Fonsêca GS, Junqueira SR, Botazzo C, de Araújo ME. (2017). Da fragmentação à formação interprofissional: proposta de um modelo de estágio curricular supervisionado para a graduação em odontologia. Saúde Redes. 2017;3(4): 410-24.

3. Chaves S, Barros SG, Santana SF, Almeida
AMFL, Santos CML, Rossi T. Política de Saúde Bucal no Brasil 2003-2014: cenário, propostas, ações e resultados. Ciênc Saúde Colet. 2017;22(6): 1791-1803.

4. Ferreira NP, Ferreira AP, Freire MCM. Mercado de trabalho na odontologia: contextualização e perspectivas. Rev Odontol UNESP. 2013;42(4): 304-9.

5. Frazão P, Narvai PC. Saúde bucal no Sistema Único de Saúde: 20 anos de lutas por uma política pública. Saúde Debate. 2009;33(81): 64-71.

6. Faé JM, Silva Junior MF, de Carvalho RB, Esposti CDD, Pacheco KTS. A integração ensino-serviço em Odontologia no Brasil. Rev ABENO. 2016;16(3):7-18.

7. Domingos PAS, Nonato $\mathrm{CN}$, Felício CM. Estágio supervisionado em odontologia: relato de experiência. J Dent Res. 2019;7(2): 18-23.

8. Ministério da Educação/Conselho Nacional de Educação/Câmara de Educação Superior. Resolução nº. 3, de 21 de junho de 2021. Institui as Diretrizes Curriculares Nacionais do curso de graduação em Odontologia e dá outras providências. [Acesso em 23 ago. 2021]. Disponível em: http://portal.mec .gov.br/index.php?option=com docman\&vi ew=download \&alias $=191741-$ rces003-21 \&category_slug=junho-2021-pdf\&Itemid= 30192.

9. Paim JS. Sistema Único de Saúde (SUS) aos 30 anos. Ciênc Saúde Colet. 2018;23(6): 1723-8.

10. Noro LRA, Moya JLM. Condições sociais, escolarização e hábitos de estudo no desempenho acadêmico de concluintes da área da saúde. Trab Educ Saúde. 2019;17(2):e0021042.

11. De Freitas SFT, Calvo MCM, de Lacerda JT. Saúde Coletiva e novas diretrizes curriculares em odontologia: uma proposta 
para graduação. Trab Educ Saúde. 2012;10(2):223-34.

12. Emmi DT, Silva DMC, Barroso RFF. Experiência do ensino integrado ao serviço para formação em Saúde: percepção de alunos e egressos de Odontologia. Interface (Botucatu). 2018; 22(64):223-36.

13. Silva AN, Senna MAA, Teixeira MCB, Lucietto DA, Andrade IM. O uso de metodologia ativa no campo das Ciências Sociais em Saúde: relato de experiência de produção audiovisual por estudantes. Interface (Botucatu). 2020; 24: e190231.

14. Rezende RSM, Oliveira AMG, Zanin L, Flório FM. Cirurgião-dentista do serviço público na formação de acadêmicos: importância do estágio em serviço. Rev Odontol Univ São Paulo. 2019;31(3):17-26.

15. Espírito Santo JA, Zocratto KBF. Ferramentas da qualidade nos processos gerenciais de serviços de saúde. Remecs. 2020;5(9):62-7.

16. Moreira MBA, Amorim MM, Santos CB, Almeida, ALPVP. Estágio em Saúde Coletiva como estratégia de reorientação da formação em odontologia: um relato de experiência Rev Saúde Com. 2020;16(1): 1766-73.

17. Neto JMAS, Nascimento TMD, Silva AS, Anjos CL, Mendonça ICG. Cuidados odontológicos no atendimento domiciliar. REAS. 2021;13(3):e6627.

18. Batista NM, Rocha ITF, Bonfante GMS. Visita domiciliar como estratégia de construção do valor saúde bucal. Arq Bras Odontol. 2019;14(2):12-5.
19. Bruder MV, Lolli LF, Palácios AR, da Rocha NB, Veltrini VC, Gasparetto A, Fujimaki M. Estágio supervisionado na odontologia: vivência da promoção da saúde e integração multiprofissional. Rev Bras Promo da Saúde. 2017;30(2):294-300.

20. Fonsêca GS, Pires FS, Junqueira SR, Souza CR, Botazzo C. Redesenhando caminhos na direção da clínica ampliada de saúde bucal. Saúde Soc. 2018;27: 1174-85.

21. De-Carli AD, Silva ADM, Zafalon EJ, Mitre SM, Pereira PZ, Bomfim RA, et al. Integração ensino-serviço-comunidade, metodologias ativas e Sistema Único de Saúde: percepções de estudantes de Odontologia. Cad Saúde Colet. 2019;27(4): 476-83.

22. Brito MCC, Grajeda FMC, Lacerda LJR, Lage CF, Modesto TC. O processo avaliativo no ensino superior com ênfase na odontologia. Rev Univ Vale Rio Verde. 2018;16(2):1-12.

\section{Correspondência para:}

Ingrid Cordeiro Monte

e-mail: ingrid_monte_@hotmail.com

Rua Antonio Acioli, 1082, Itaperi

60714-215 Fortaleza/CE 